\title{
A Study on the Standardization of the Test Method Upon Testing the Anterior Cruciate Ligament Damage Using TELOS
}

\author{
Jongcheon Lim, Dongkyoon Han* \\ Dep. of radiology Yanyang Univsity. Hospital, Dep. radiological science, college health science Eulji University ${ }^{*}$

\section{TELOS를 이용한 Knee Stress (Lachman)검사의 표준화에 대한 연구} \\ 임종천, 한동균 ${ }^{*}$ \\ 한양대의료원 영상의학과, 을지대학교 보건과학대학 방사선학과*
}

\begin{abstract}
This study aims to find out the standardized test criteria regarding patients with the anterior cruciate ligament damage by identifying the degree of the flexion gap of femur and tibia upon bending of the anterior cruciate ligament in order to carry out the accurate test of such impairment. On the standardized test method and judgement criteria upon the anterior cruciate ligament test using Telos, it has been shown that there was no significant difference in the results according to the position of a fixed roller in the anterior cruciate ligament test for normal patients. However, in a test for patients who had undergone the anterior cruciate ligament reconstruction, it has been shown that the measured values of the anterior cruciate ligament tended to be pushed when the position of a fixed roller was less than $1 \mathrm{~cm}$ in the test according to the position of a fixed roller of Telos (less than $1 \mathrm{~cm}$, more than $3 \mathrm{~cm}$ ), and this was statistically significant. The anterior cruciate ligament test (knee stress test) is a limited method used in orthopedics and rehabilitation medicine, and there have been no standardized test guidelines available yet although numerous ligament measurement tests have been performed. In addition, since the measured values are often different depending on testers even on the test that is expected to give the same result, the reproducibility of the test is still low.

Accordingly, it is considered that the criteria for the anterior cruciate ligament test need to be established, and this would contribute to the accuracy of the diagnosis through the accurate test and standardized measurements.
\end{abstract}

Key Words : Telos1, Anterior cruciate ligament, lachman-test(Knee stress-test)

\section{요 야}

전방 십자 인대는 슬관절에서 가장 중요한 구조물로써 경골의 전방 전위 시 전체 위력에 대한 저항의 약 $86 \%$ 를 차 지하고 회전의 축을 이루고 있어서 슬관절의 안정성을 유지 하는 기능을 한다. 슬관절의 인대 검사 장비인 TELOS 장 비로 Lachman 검사 시 정상 측과 수술 측 모두 인가되는 힘에 비례 하여 선형적으로 무릎의 굴곡이 일어났으며, 검 
사 시 외부 힘에 따라 무릎 굴곡이 발생하여 무릎 권고 각도의 유지하기가 어려웠다. 대퇴 고정 롤러의 위치를 슬개골 위 $1 \mathrm{~cm}$ 미만과 $3 \mathrm{~cm}$ 이상에 위치 시켜 동요를 측정하여 롤러 위치에 따른 대응t 검정을 실시하였으며, 그 결과 롤러의 위치 $1 \mathrm{~cm}$ 이었을 때 무를 동요에 유의한 차이를 보였다 $(\mathrm{p}<.05)$. 또한 무릎의 굴곡 각도와 동요의 상관분석을 통해 두 변수 사이에는 상관성이 없는 것으로 나타났으며 이는 Telos Device를 이용한 전방십자인대 검사는 무릎의 굴곡각 도 보다는 대퇴 고정롤러의 위치에 영향을 받는 것으로 판단되며 따라서 대퇴 고정롤러의 위치를 슬개골 가까이 위치 시키는 것이 대퇴골을 안정적으로 고정 시키고 경골의 움직임을 유발하여 정확한 무릎 관절의 동요를 진단 할수 있는 검사 방법이라 사료된다.

중심단어: TELOS STRESS DEVICE, 전방십자인대, Lachman

\section{I. 서 론}

고속경제 성장으로 인한 국민 GNP상승 및 주 5일 제 근무 등 여가 시간이 증대 되면서 현대인의 평일 여가활동으로 가장 많이 이용 하는것은 운동(24.8\%)으 로 나타났다. 이는 여가 활동의 패턴이 휴식형태의 여 가에서 활동적인 스포츠로 변모하고 있다는 것을 의 미한다 ${ }^{[1]}$. 최근 다양한 스포츠 활동이 증가하면서 삶 의 질을 높이고자 스포츠 활동에 참여하는 인구가 늘 고 있으며, 그에 따라 부상의 위험에 많이 노출되고 있다. 그 중에서도 슬관절 손상이 가장 많이 일어나고 있다 ${ }^{[2]}$. 슬관절을 지지해 주는 인대와 관절 주의의 근 육들은 슬관절의 안정성을 유지하는 데 중요한 역할 을 하는데 ${ }^{[3]}$, 그 중에서도 전방 십자 인대는 슬관절에 서 가장 중요한 구조물로써 경골의 전방 전위 검사 시 전체 위력에 대한 저항의 약 $86 \%$ 를 차지하고 회전의 축을 이루고 있어서 슬관절의 안정성을 유지하는 기 능을 한다다. 전방 십자인대의 기능에 이상이 생길 경 우 스포츠 활동을 비롯한 회전량이 많은 활동에 장애 를 줄 뿐만 아니라 적절한 치료시기를 놓치게 되면 반 월상 연골의 손상이나, 대퇴 경골간 관절의 퇴행성 관 절염이 조기에 유발될 수 있다 ${ }^{[5]}$. 건강보험심사평가원 자료를 토대로 분석한 연구에 의하면 무릎을 다쳐 입 원한 환자 중 무릎 내부 이상(십자인대 파열, 연골파열 등)으로 입원한 환자는 2012년 56,679명으로 2011년 (45,966명)에 비해 무려 $23.3 \%$ 나 증가했다 ${ }^{[6]}$. 슬관절인 대의 손상에 대한 진단적 검사로는 이학적 검사,단순 방사선 촬영, 자기 공명 영상(MRI), TELOS STRESS DEVICE, KT2000 등이 있다. 이학적 검사는 문진, 청 진, 촉진등에 의한 의사의 주관적 소견의 진단이어서 객관적 진단이 부족하며, MRI검사는 인대의 상태를
해부학적으로 잘 표현해 줄 수 있으나 검사 비용이 고 가이고, 무를 인대의 기능적 검사를 하는 데는 한계가 있다. KT2000 Knee Ligament Arthrometer는 전 후방 전 위를 객관적으로 측정하는 장비이며, Lachman 검사를 정량화한 것이나, 무릎의 굴곡 및 회전에 대한 영향 인자를 내재하고 있으며군 국내 수도권 13개 병원 중 4개 병원(69.2\%) 에서만 KT 2000검사를 시행 하고 있 어 검사 비율이 Telos Device 에 비해 상대적으로 낮다. Telos Stress Device는 장비를 이용하여 경골(Tibia)에 힘 을 가하여 방사선 촬영(X-ray) 후 그 영상으로 대퇴골 (Femur)과 경골의 동요 (displacement)를 측정하고, 슬관 절 전방 십자인대 손상과 기능적 측면의 정확한 진단 을 평가하는 데는 유용한 검사 방법이나 검사자, 장비 조립 방법에 따라 검사의 재연성이 다른 경우가 있다. X-ray 검사는 방사선사가 직접 다루며 촬영해야 한다 ${ }^{[8]}$. 따라서 본 논문은 무릎 관절의 굴곡력이 동요에 어 떠한 영향을 미치는 지를 규명하고, 이 들 굴곡력, 대 퇴고정 골러 위치와 무릎의 동요간의 인자가 어떠한 상관 관계가 있는 지 확인하여 객관적인 검사 방법을 계획하고자 하였다.

\section{II. 대상 및 방법}

\section{1. 검사 대상 및 방법}

연구 대상은 2013년 3월부터 8월까지 6개월간 H병 원으로 내원한 환자 중 전방십자인대 재건술(ACL Reconstruction)을 시행한 환자 총 24명을 대상으로 시 행하였다. 환자 검사 시행 시 전방십자인대 재건술 (ACL Reconstruction)을 시행한 환측과 재건술을 시행 하지 않은 건측을 대상으로 양측 모두에 대하여 검사 를 시행하였다. 환자의 환측과 건측에 대하여 아래와 
같이 Femur roller 위치를 변경시켜 각각 두 번 검사를 시행하였다. Femur Roller location(d)이 Patella upper margin $1 \mathrm{~cm}$ 이내에 위치하며, Pressure Device(d')는 plateau 아래 $3 \mathrm{~cm}$ 에 위치시킨다[Fig. 1].
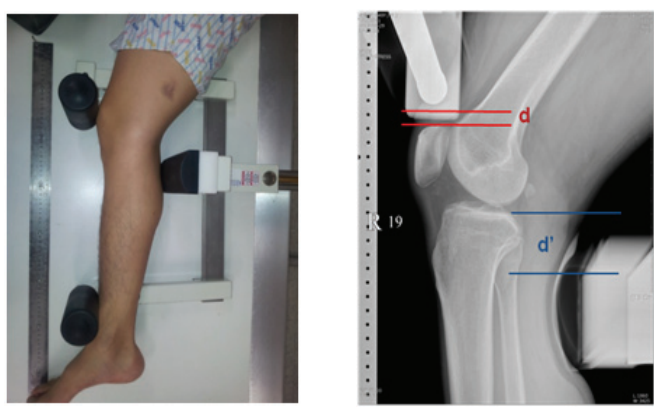

Fig. 1. Femur roller lie $1 \mathrm{~cm}$ upper patella.

Femur Roller location(d)는 Patella upper margin $3 \mathrm{~cm}$ 이상, Pressure Device location(d ') 는 plateau 아래 $3 \mathrm{~cm}$ 에 위치시킨다[Fig. 2].
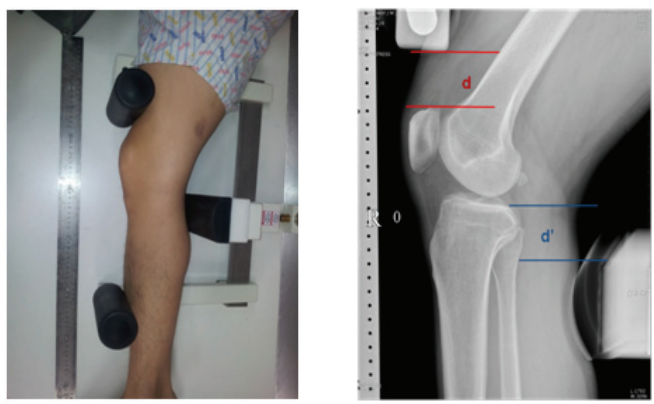

Fig. 2. Femur roller lie $3 \mathrm{~cm}$ more upper patella.

Fig. 1의 환자는 옆으로 누운 자세에서 Femur와 Tibia의 장축이 $20^{\circ} \sim 30^{\circ}$ 를 이루도록 하고, Femur Roller와 Tibia Roller사이에 무릎 관절을 위치시킨다. 이때 Femur roller를 슬개골 상연 $1 \mathrm{~cm}$ 미만, Pressure Device를 tibia plateau아래 $3 \mathrm{~cm}$ 지점에 위치시킨 후, Scout Image를 통해 위의 모든 조건에 맞게 환자 및 장 비가 정확하게 위치하였는지 확인한다.

Pressure Device를 환자의 앞쪽으로 가해지는 힘이 0 $\mathrm{daN}, 10 \mathrm{daN}, 15 \mathrm{daN}, 20 \mathrm{daN}, 25 \mathrm{daN}$ 에서 검사를 시행 하였다.

\section{2. 측정방법}

\section{1 측정기준선}

Pressure power 가 인가됨에 따라 tibia 의 회전이 발 생하며[Fig. 3], 이에 따라 $\mathrm{H}$ 병원 재활의학과 임상의 2 명에게 전방십자 인대 검사 영상을 평가 의뢰하고, 객 관적인 측정을 위하여 측정 기준 선을 양측 Femoral posterior condyle이 겹친 지점과 tibia plateau의 수직된 양측 tibia condyle 중간 지점을 잊는 선을 측정 기준선 으로 제시하였다.

\subsection{Pressure power 에 따른 영향}

\subsection{1 무릎 굴곡 (Femur-Plateau) 측정}

십자인대의 정확한 측정을 위하여 주위 근육을 이 완시켜야 하고 이를 위해서는 Femur -Tibia axis angle(F-T angle)이 $20^{\circ} \sim 30^{\circ}$ 를 이루도록 권고하고 있다 [7]. F-T angle을 측정 재연성을 높이기 위하여 Femur-Tibia Plateau angle(F-P angle)로 변환 하면, F-T angle은 $20^{\circ} \sim 30^{\circ}$ 이고, F-P angle은 $70^{\circ} \sim 80^{\circ}$ 와 같으며 [Fig. 4], 0 25daN의 힘을 인가하여 건측과 환측의 무릎 의 굴곡의 변화를 측정하였다.

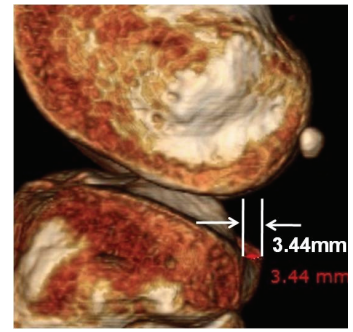

(a) 0 daN

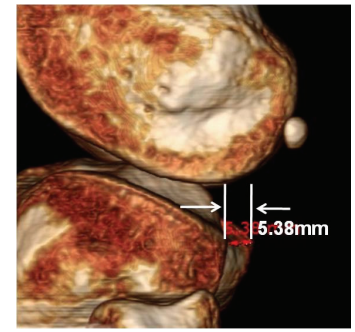

9b) $15 \mathrm{daN}$

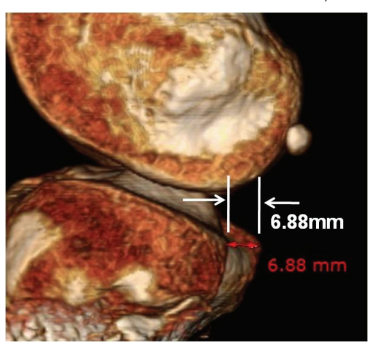

(c) $25 \mathrm{daN}$

Fig. 3. Measured according to the rotation of tibia condyle daN. 
2.2.2. 무릎 동요 (displacement) 측정

2.2.1과 동일한 방법으로 환자의 자세를 유지하고, 건측과 환측에 $0 \sim 25 \mathrm{daN}$ 의 힘을 인가하여, 무릎의 동 요를 측정하였다.

\subsection{Femur Roller 위치에 따른 영향}

2.3.1 무를 굴곡 (Femur-Plateau angle) 측정

환자의 환측의 Femur 고정 roller의 위치를 patella 위 $1 \mathrm{~cm}$ 미만과 $3 \mathrm{~cm}$ 이상에 위치 시켜 각 1 회 총 2 회 검 사를 시행하며, 이 때 Pressure Device는 경골 Plateau 아 래 $3 \mathrm{~cm}$ 지점에 위치시켜 $10,15,20,25 \mathrm{daN}$ 의 힘을 인 가하여, F-P angle을 측정하였다

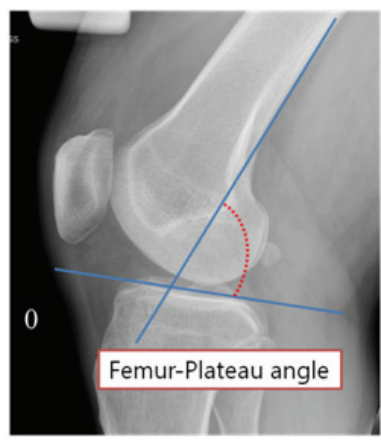

Fig. 4. F-P angle.

\subsection{2. 무릎 동요 (displacement) 측정}

2.3.1 과 동일한 방법으로 환측에 검사를 시행하며, 이 때 무릎의 동요를 측정 하였다.

\section{4 분석방법}

통계처리는 SPSS Inc, Chicago, IL, U.S.A 프로그램을 이용하여 모든 분석에 $\mathrm{p}$ 값이 0.05 미만일 경우를 유의 한 것으로 판단하였다. Pressure power에 Femur roller 위치에 따른 무릎의 굴곡과 동요의 집단 간 차이검증 은 ANOVA test 로 집단 간 분석 후 LSD 다중 분석 비 교로 검정하였으며, Femur roller 위치에 따른 차이는 Paired test를 실시하였다. 무릎의 굴곡과 Femur roller 위치의 상관분석을 통해 상관성을 검증하였다.
III. 결 과

\section{Pressure power 에 따른 영향}

\section{1 무릎 굴곡 측정}

\subsection{1 건측결과}

인가된 힘에 따른 집단 간 분석 및 $\mathrm{LSD}$ 분석 값은 높은 유의한 차이( $\mathrm{p}<.05)$ 의 굴곡을 보였으며[Table 1], 무릎 굴곡각도의 평균 및 표준편차는 $10 \mathrm{daN}$ 은 $62.66 \pm 6.27,15 \mathrm{~d} a \mathrm{~N}$ 은 $60.58 \pm 7.05,20 \mathrm{daN}$ 은 $58.53 \pm 7.36$, $25 \mathrm{daN}$ 은 $56.12 \pm 8.6$ 이다. 힘 인가에 따른 $5 \mathrm{daN}$ 마다 굴 곡 각도는 $2.60,2.08,2.06,2.41$ 이고, 평균 2.28 의 굴곡 을 보였다.

Table 1. Normal side analysis

\begin{tabular}{cccl}
\hline & Pressure power & Pressure power & *p \\
\hline \multirow{2}{*}{$10 \mathrm{daN}$} & $20 \mathrm{daN}$ & .045 \\
& $25 \mathrm{daN}$ & .002 \\
\cline { 2 - 4 } & \multirow{2}{*}{$15 \mathrm{daN}$} & $0 \mathrm{daN}$ & .024 \\
& $25 \mathrm{daN}$ & .031 \\
\cline { 2 - 4 } Normal & \multirow{2}{*}{$20 \mathrm{daN}$} & $0 \mathrm{daN}$ & .001 \\
& & $10 \mathrm{daN}$ & .045 \\
\cline { 2 - 4 } & \multirow{2}{*}{$25 \mathrm{daN}$} & $0 \mathrm{daN}$ & .000 \\
& & $10 \mathrm{daN}$ & .002 \\
& & $15 \mathrm{daN}$ & .031 \\
\hline & & LSD Mul tiple Compar ison by ANOVA
\end{tabular}

\subsection{2 환측결과}

건측과 동일한 방법으로 $10 \sim 25 \mathrm{daN}$ 을 변화 시켜 입 력 하였으며, $\mathrm{daN}$ 힘의 집단 간 분석값은 유의한 차이 를 보이며 $(\mathrm{p}<.05)$, 무릎의 굴곡이 있음을 보여 준다 (Table 2). 다중비교분석에서도 각 $\mathrm{daN}$ 별 유의한 차이 를 보여준다. 무를 굴곡의 평균및 표준편차는 $10 \mathrm{daN}$ 은 $61.08 \pm 6.27,15 \mathrm{daN}$ 은 $59.51 \pm 7.05,20 \mathrm{daN}$ 은 $56.96 \pm 7.36,25 \mathrm{daN}$ 은 $54.18 \pm 8.6$ 이다. $5 \mathrm{daN}$ 별 굴곡 각 도는 $2.71,2.52,2.65,2.73$ 이고 평균 $2.65^{\circ}$ 굴곡을 보였 으며, 건측과 환측의 무릎의 굴곡 독립 $\mathrm{t}$ 검정 결과 유 의한 차이는 없었다.(p>.05) 
"J. Korean. Soc. Radiol., Vol. 8, No. 2, February 2014"

Table 2. Operate side analysis

\begin{tabular}{|c|c|c|c|}
\hline \multicolumn{3}{|c|}{ Pressure power } & $\star p$ \\
\hline $\begin{array}{l}\text { Operate } \\
\text { side }\end{array}$ & 10daN & $25 \mathrm{daN}$ & .015 \\
\hline
\end{tabular}

\section{2 무릎동요(displacement) 측정}

분산의 동질성검정을 통해 건측 $\mathrm{p}=0.938$, 환측 $\mathrm{p}=0.994$ 로서 각 수준별 등분산이 만족되어 LSD 사후 분석을 실시하였다.

\subsection{1 건측결과}

건측의 경우 인가되는 힘에 따른 유의한 동요는 없 었으며(Table 3.) 계측값으로 보았을 때 $10 \mathrm{daN}$ 과 $25 \mathrm{daN}$ 구간에서는 평균 $0.73 \mathrm{~mm}$ 의 차이를 보였다. $10 \mathrm{daN}$ 의 평균과 표준편차는 $2.63 \pm 2.11,15 \mathrm{daN}$ 은 $3.23 \pm 2.30$, $20 \mathrm{daN}$ 은 $3.33 \pm 2.39,25 \mathrm{daN}$ 은 $3.36 \pm 2.39$ 이다.

Table 3. Normal side analysis between pressure power

\begin{tabular}{|c|c|c|c|}
\hline & \multicolumn{2}{|c|}{ Pressure power } & \multirow{2}{*}{$\begin{array}{c}\star \mathrm{p} \\
.370\end{array}$} \\
\hline \multirow{12}{*}{$\begin{array}{c}\text { Normal } \\
\text { side }\end{array}$} & & $15 \mathrm{daN}$ & \\
\hline & $10 \mathrm{daN}$ & $20 \mathrm{daN}$ & .296 \\
\hline & & $25 \mathrm{daN}$ & .275 \\
\hline & & 10daN & .370 \\
\hline & $15 \mathrm{daN}$ & $20 \mathrm{daN}$ & .881 \\
\hline & & $25 \mathrm{daN}$ & .844 \\
\hline & & 10daN & .296 \\
\hline & 20daN & $15 \mathrm{daN}$ & .881 \\
\hline & & $25 \mathrm{daN}$ & .962 \\
\hline & & 10daN & .275 \\
\hline & $25 \mathrm{daN}$ & $15 \mathrm{daN}$ & .844 \\
\hline & & $20 \mathrm{daN}$ & .962 \\
\hline
\end{tabular}

\subsection{2 환측결과}

$\mathrm{LSD}$ 사후분석 다중분석비교결과 환측은 $10 \sim 20 \mathrm{daN}$ 의 상호 유의한 차이는 없으나, $10 \mathrm{daN}$ 과 $25 \mathrm{daN}$ 과는 유의한 차이 $(<0.05)$ 를 보여, 건측과는 달리 환측의 경 우 인가 압력에 대한 무릎 동요에 영향을 받는 것을 알 수 있다[Table 4]. 수치 결과는 $5 \mathrm{daN}$ 별로 평균 $0.93 \mathrm{~mm}$ 의 평균차를 보였다. $10 \mathrm{daN}$ 의 평균과 표준편차 는 $5.57 \pm 4.21,15 \mathrm{daN}$ 은 $7.04 \pm 3.98,20 \mathrm{daN}$ 은 $7.73 \pm 4.04$, $25 \mathrm{daN}$ 은 $8.38 \pm 4.24$ 이다.
Table 4. Operate side analysis between pressure power

\begin{tabular}{|c|c|c|c|}
\hline & \multicolumn{2}{|c|}{ Pressure power } & $\star p$ \\
\hline \multirow{12}{*}{$\begin{array}{c}\text { Operate } \\
\text { side }\end{array}$} & \multirow{3}{*}{ 10daN } & $15 \mathrm{daN}$ & .221 \\
\hline & & 20daN & .072 \\
\hline & & $25 \mathrm{daN}$ & .020 \\
\hline & \multirow{3}{*}{$15 \mathrm{daN}$} & 10daN & .221 \\
\hline & & 20daN & .559 \\
\hline & & $25 \mathrm{daN}$ & .263 \\
\hline & \multirow{3}{*}{ 20daN } & 10daN & .072 \\
\hline & & $15 \mathrm{daN}$ & .559 \\
\hline & & $25 \mathrm{daN}$ & .590 \\
\hline & \multirow{3}{*}{$25 \mathrm{daN}$} & 10daN & .020 \\
\hline & & $15 \mathrm{daN}$ & .263 \\
\hline & & 20daN & .590 \\
\hline
\end{tabular}

\section{Femur Roller 위치에 따른 영향}

\section{1 무릎굴곡(Femur-plateau angle) 측정}

환측의 롤러 위치 $1 \mathrm{~cm}$ 과 $3 \mathrm{~cm}$ 에 따른 대응표본 $\mathrm{t}$ 검정 결과 유의한 차이를 보여 $(\mathrm{p}<.05)$, 롤러 위치에 따 라 무릎의 굴곡 각도가 다름을 알 수 있다(Table 5). 롤러위치에 따른 무릎굴곡 평균과 표준편차는 $1 \mathrm{~cm}$ 은 $62.76 \pm 7.37,3 \mathrm{~cm}$ 은 $57.32 \pm 6.52$ 로서 롤러 위치 $3 \mathrm{~cm}$ 에서 더 많은 무릎의 굴곡이 있음을 알 수 있다.

Table 5. Knee flexion analysis to roller $1 \mathrm{~cm}$ and $3 \mathrm{~cm}$

\begin{tabular}{ccccc}
\hline & Mean & SD & $\mathrm{t}$ & $\mathrm{p}$ \\
\hline $\begin{array}{c}\text { Femur-Plateau } \\
\text { angle }\end{array}$ & 5.440 & 6.438 & 4.139 & .000 \\
\hline
\end{tabular}

p-value by paired t-test

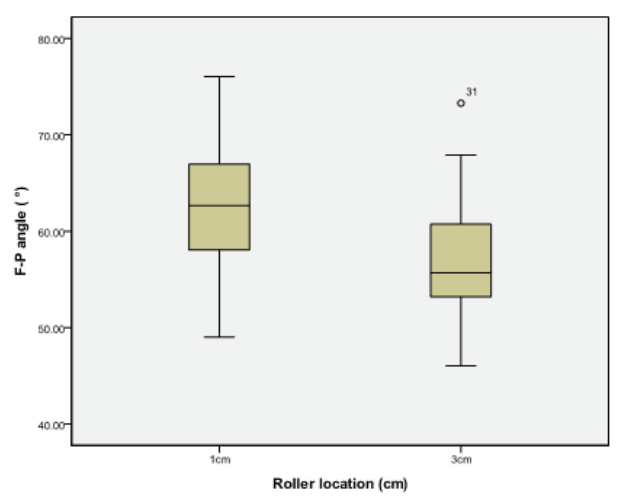

Fig. 5. Assess for Femur-Plateau angle accordingf to Femur Roller location 


\section{2 무릎동요(displacement) 측정}

롤러위치 $1 \mathrm{~cm}$ 과 $3 \mathrm{~cm}$ 에 따른 대응 표본 $\mathrm{t}$ 검정결과 $\mathrm{t}$ 값이 $3.72, \mathrm{p}<.00$ 로서 롤러위치에 따른 유의한 차이를 보이며, $1 \mathrm{~cm}$ 에서 더 많은 무릎의 동요가 발생하는 것 을 알 수 있다(Table 6). $1 \mathrm{~cm}$ 에서 무릎동요 평균과 표 준편차는 $7.49 \pm 3.65,3 \mathrm{~cm}$ 은 $6.51 \pm 3.45$ 이다.

Table 6. Displacement analysis to roller $1 \mathrm{~cm}$ and $3 \mathrm{~cm}$

\begin{tabular}{lllll}
\hline & Mean & SD & $t$ & $p$ \\
\hline Displacement & 0.98 & 1.30 & 3.72 & .001 \\
\hline
\end{tabular}

\section{3 무릎각도와 동요의 상관관계}

롤러위치 $1 \mathrm{~cm}$ 과 $3 \mathrm{~cm}$ 으로 달리한 무릎각도와 동 요의 상관분석 결과 롤러위치 $1 \mathrm{~cm}$ 이었을 때 $(\mathrm{r}=.082$, $\mathrm{p}>.05)$ 와 $3 \mathrm{~cm}$ 이었을 때 $(\mathrm{r}=.244, \mathrm{p}>.05)$, 두 개의 변수 는 유의한 상관관계가 없으며, 산점도 에서도 무릎굴 곡과 동요의 2 차원 이상의 뚜렷한 관계가 나타나지 않 고 측정치들의 퍼짐과 경향성이 산발적인 결과를 보 임으로 유의한 상관관계가 없음을 알 수 있다.

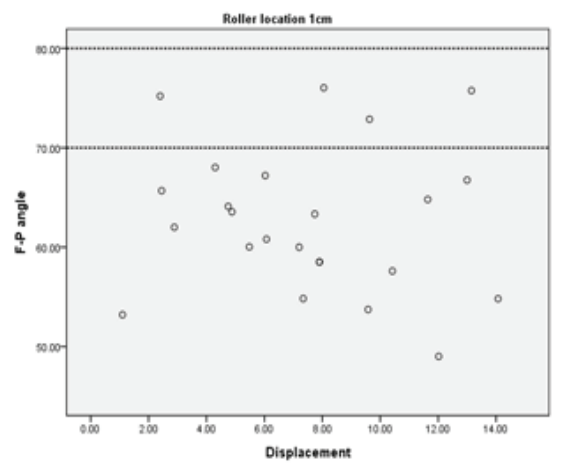

(a) Correalation knee flxion and displacement on roller $1 \mathrm{~cm}$

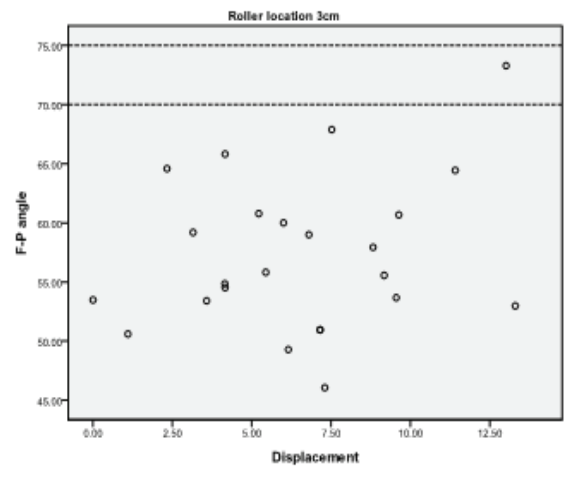

(b) Correalation knee flxion and displacement on roller $3 \mathrm{~cm}$

Fig. 6. Correalation knee flxion and displacement(a), (b).

\section{$\mathrm{IV}$. 고 찰}

Pressure device 의 인가되는 힘이 증가 될수록 $15 \mathrm{daN}$ 이상 부터는 십자인대 lachman 검사의 권고 자 세인 무를굴곡(Femur-Tibla angle 20 30 $)$ 의 유지는 어 려웠다. Matsumoto 는 사체 및 정상 대조군과 한쪽 슬 관절 전방 십자인대 손상이 있는 환자를 대상으로 KT-2000 arthormeter 를 이용하여 측정한 결과 정상군 의 경우 평균 $20 \mathrm{lb}(10 \mathrm{daN})$ 에서 평균 $5.7 \mathrm{~mm}$ 의 전방 전 위 소견을 보였으며, 환자군은 평균 $13 \mathrm{~mm}$ 의 정방 전 위 소견을 보였다 ${ }^{[9]}$ 고 하였으며, 임준택은 전방십자인 대는 탄성을 가지고 있다 ${ }^{[10]}$ 고 하여, 정상인대도 일정 한 힘에 의한 제한적인 동요가 있을 수 있음을 제시 하였다. 그러나 본 연구의 Telos Device 에서는 건측의 전방위 소견인 무릎동요는 통계적 유의성은 없었으나, 그래프를 통한 결과로는 유사한 결론을 내릴 수 있었 다. 십자인대 수술 후 초기 건측과 환측의 인대기능의 차이는 있으나 ${ }^{[10]}$, 수술 후 재활운동으로 꾸준하고 체 계적인 재활 시 건측과 환측의 십자인대 기능의 차이 는 유의한 차이가 없다 ${ }^{[11]}$. 이는 주위 근력의 향상과 함께 무릎의 기능이 정상적인 수준까지 회복된 것으 로 볼 수 있다 ${ }^{[12]}$ 고 하였다. 본 연구에서는 환측, 건측 모두 $20 \mathrm{daN}$ 까지 동요의 유의한 차이는 없으나, 환측 의 $25 \mathrm{daN}$ 에서는 유의한 차이가 있는 것으로 분석되 었다. 이는 현재 대 다수의 병원에서 시행되고 있는 십자이대 재건술을 대상으로 한 검사 시 $15 \mathrm{daN}$ 의 힘 
이 인가되고 있는 점을 고려할 때 $25 \mathrm{daN}$ 인가 시 슬관 절 동요에 대한 임상적 연구가 필요 하리라 생각 된다. 환측의 Femur roller 의 위치에 따른 무를굴곡 및 동요 의 결과는 $3 \mathrm{~cm}$ 롤러 위치가 유의한 차이로 더 많은 굴 곡을 보였으며, 동요는 롤러위치 $1 \mathrm{~cm}$ 미만일 때 더 많 은 동요가 유의하게 발생하였다. 무릎 굴곡이 주위 근 육을 이완시켜 무릎 관절 동요에 미치는 영향을 분석 한 상관분석에서 무를굴곡과 동요는 상관관계를 보이 지 않았다. 다른 ACL검사 $90^{\circ}$ flexion drawer study는 무 릎각도 $90^{\circ}$ 상태에서도 전방십자인대의 기능검사가 되 고 있는 것을 미루어 볼 때, TELOS DEVICE STRESS 검사는 무릎의 각도보다는 Femur 고정 roller의 위치에 유의한 차이가 있는 것으로 판단된다.

\section{$\mathrm{V}$. 결 론}

전방십자인대 검사(Knee stress 검사)는 ligament 측 정을 하는 한정된 방법의 하나로서 수많은 인대측정 검사를 시행했음에도 아직까지 표준화된 검사 지침이 마련되지 않고 있으며, 검사자에 따라 동일한 검사를 시행함에도 검사 계측수치가 달리 나오는 경우가 있 다. 근육의 특성은 성별, 신체적 조건에 따라 개인마다 매우 상이함을 알 수 있으며 ${ }^{[13]}$, 본 연구는 정상인 환 자와 전방십자인대 재건술(ACL Reconstruction)을 시행 한 환자 각 24명을 대상으로 telos를 통한 lachman 검사 를 시행하여, 고정 roller의 위치 $(1 \mathrm{~cm}$ 미만, $3 \mathrm{~cm}$ 이상 $)$ 에 따라 대퇴골과 경골의 동요를 비교하여 유의한 차이 가 있었다. 따라서 무릎 관절의 전방십자인대 손상 환 자의 검사 시 표준화된 검사 방법 및 판단 기준을 제 시하고자 하였으며, 대퇴부 고정롤러의 위치를 슬개골 에 $1 \mathrm{~cm}$ 미만에 위치시켜 검사하는 것을 제안하는 바 이다. 또한 검사 시 장비의 정확한 조립은 정확한 진 단을 내리는 데 기초가 되리라 사료된다.

\section{참고문헌}

[1] HaeSeong Kim, Journal of Sport and Leisure Studies, Vol. 47, pp. 171 184, 2012.

[2] Eun-Hae Kim, "Knee flexor and function correlation after Anterior Cruciate Ligament tear", Korea Univ. graduate, 2009.

[3] Marshall JL, Rubin RM, "Knee ligament injuries.A diagnostic and therapeutic approach", Orthop Clin North Am 8:641-668,
1977.

[4] Ki-Seok Min, "The effects of Home-based Exercise Rehabilitation in Patients with parital Anterior Cruciate Ligament Injury",Vol.11. P1, 2004.

[5] Yoon-Su Nam, "Estimation of Muscle-tendon Model Parameters Based on a Numeric Optimiz ation", Journal of the Korean Society for Precision Engineering, Vol. 26, pp. 123, 2009.

[6] Kook-Won Park, "Information of useful medical" "The Gyeong-gi Shinmun", Vol. 8, No. 29, p. 17, 2013.

[7] Jae-Hyung Park, "The Benefit of KT-2000 Knee Ligament Arthormeter in Diagnosis of Anterior Cruciate Ligament Injury", Journal of Korean Arthroscopy Soc., Vol. 2, 2004.10

[8] Byeoungju Ahn,"Radiographic Status of the Visited Patients at University Hospital Emergeny Room" Journal of the Korean

Society of Radiology, Vol. 5, Numver 2, 2011.4

[9] Mstsumoto,H. et al., "Journal-Japanese orthopaedic association", Vol. 67 No. 2, 1993.

[10] Joon-Taek Lim, "A Study on Mechanical Characteritic of Human Cruciate Ligament and Annulus Fibros using Fiber-reinforced Hyperelastic Material Model", Dan Kook Univ., pp. 23

[11] Gerber C.,Hoppeler H.0, Claassen R., Robotti G, Zehnder R.. and Jakob.r, "Lower extremity musclature in chronic symptomatic instability of the anterior cruciate ligament", J Bone Joint Surg., Vol. 65A, pp. 1034-1043, 1985.

[12] Yong-Kwon Kim, "The Effects of a 12-week exercise training program on ligament stability, knee function, and lysholm score after anterior cruciate ligament reconstruction", Seoul Univ. graduate, pp. 78, 2002.

[13] Eun- Kun Lee, "The Study of Knee Joint Functional Performance Test and Muscular Strength Different after Anterior Cruciate Ligament Recon struction", Kook Min Univ. graduate, pp. 28, 2007 . 